\title{
Trivium
}

Revue franco-allemande de sciences humaines et sociales - Deutsch-französische Zeitschrift für Geistesund Sozialwissenschaften

$14 \mid 2013$

Le Saint-Empire à l'époque moderne

\section{Drinnen und draußen. Raum und Identität der Exklave im Alten Reich nach dem Westfälischen Frieden}

\section{Christophe Duhamelle}

Traducteur : Falk Bretschneider

\section{OpenEdition}

Journals

Édition électronique

URL : http://journals.openedition.org/trivium/4630

ISSN : 1963-1820

\section{Éditeur}

Les éditions de la Maison des sciences de l'Homme

Référence électronique

Christophe Duhamelle, « Drinnen und draußen. Raum und Identität der Exklave im Alten Reich nach dem Westfälischen Frieden », Trivium [Online], 14 | 2013, online erschienen am 16 September 2013 , abgerufen am 07 September 2020. URL : http://journals.openedition.org/trivium/4630

Ce document a été généré automatiquement le 7 septembre 2020

\section{(c) (i) (9)}

Les contenus des la revue Trivium sont mis à disposition selon les termes de la Licence Creative Commons Attribution - Pas d'Utilisation Commerciale - Pas de Modification 4.0 International. 


\title{
Drinnen und draußen. Raum und Identität der Exklave im Alten Reich nach dem Westfälischen Frieden
}

\author{
Christophe Duhamelle \\ Traduction : Falk Bretschneider
}

\section{NOTE DE L'ÉDITEUR}

Wir danken Herrn Christophe Duhamelle sowie den Presses universitaires du Septentrion für die freundliche Genehmigung, diesen Artikel in deutscher Übersetzung zu publizieren.

Nous remercions M. Christophe Duhamelle ainsi que les Presses universitaires du Septentrion de nous avoir accordé l'autorisation de traduire ce texte pour le présent numéro.

1 Eine Exklave ist ein Stück Land, das sich völlig abgetrennt vom Hauptteil eines Territoriums befindet. Wenn man vom Zentrum aus startet, muss man also eine oder mehrere andere politische Einheiten durchqueren, um in die Exklave zu gelangen. Diese unterscheidet sich mithin von einer "Enklave« - ein Begriff, der vertrauter ist und eine Raumeinheit bezeichnet, die völlig von einem anderen Territorium umschlossen ist, zu dem sie nicht gehört. Eine Enklave ist nicht unbedingt eine Exklave und umgekehrt. Im heutigen Europa etwa bildet die Republik von San Marino zwar eine in Italien gelegene Enklave, aber sie hängt von keinem anderen Land ab. Die Region Kaliningrad (das ehemalige Königsberg) hingegen ist eine russische Exklave, jedoch keine Enklave, denn sie grenzt sowohl an Polen als auch an Litauen und die Ostsee. In diesem Beitrag wird es um die Exklaven innerhalb des Alten Reichs gehen. Das schließt die Exklaven des Reichs selbst aus, wie sie etwa von Matthias Schnettger für Italien untersucht worden sind ${ }^{1}$ - es sei denn, diese reichischen Exklaven bildeten gleichzeitig Einheiten, die von einem Territorium abhängig waren, wie etwa im Fall von Mömpelgard (Montbéliard), das eine Exklave des Herzogtums Württemberg wie auch 
eine Exklave des Reichs war. ${ }^{2}$ Wir interessieren uns hier folglich für jene kleinen Stücke Preußens, Sachsens oder eines anderen Fürstentums, die nicht direkt mit dem Hauptteil verbunden waren.

Dieses Interesse mag eigenartig erscheinen. Für manche gleicht es vielleicht dem Forscherdrang eines territorialen Insektenforschers, der nach einer höchst seltenen Mutation sucht. Schließlich gibt es in Westeuropa heute nur noch vier Exklaven einer Nation in einer anderen. ${ }^{3}$ Im Alten Reich jedoch war dieses Phänomen alles andere als rar. Um sich davon zu überzeugen, reicht es, die drei auf den folgenden Seiten präsentierten Karten etwas näher zu betrachten. Alle drei (wie auch die Karten, die wir später noch sehen werden) sind nach zwei Prinzipien angefertigt: größtmögliche Präzision durch die Einbeziehung regionaler Geschichtsatlanten ${ }^{4}$ sowie anschließend Reduktion auf eine "Silhouette« ohne Namen, ohne Maßstab, ohne geographische Orientierungspunkte wie Flüsse oder Städte und ohne Angabe der Nachbarterritorien. Besonders hervorgehoben wird dadurch der Umriss der Territorien. Möglicherweise erinnern diese drei Abbildungen an einen wohlbekannten psychologischen Test oder rufen Anklänge an eine (sehr unwahrscheinliche) deutsche Variante der polynesischen Inselwelt hervor. Es handelt sich jedoch um drei Kurfürstentümer (die eminentesten der Fürstentümer des Alten Reichs ${ }^{5}$ ), wobei eines das ranghöchste und ein anderes das mächtigste unter ihnen darstellte. $\mathrm{Zu}$ sehen sind, in dieser Reihenfolge, das kurfürstliche Erzbistum Mainz, der westliche Teil jenes territorialen Aggregats, das man just zu jener Zeit begann, die preußische Monarchie zu nennen, und schließlich das Kurfürstentum des Pfalzgrafen bei Rhein. In allen Fällen ist die Silhouette zerstückelt und voller Zacken, und sie zeigt eine fast beliebige Vielfalt von skurrilen Grenzsituationen.

Das Kurfürstentum Mainz nach 1648

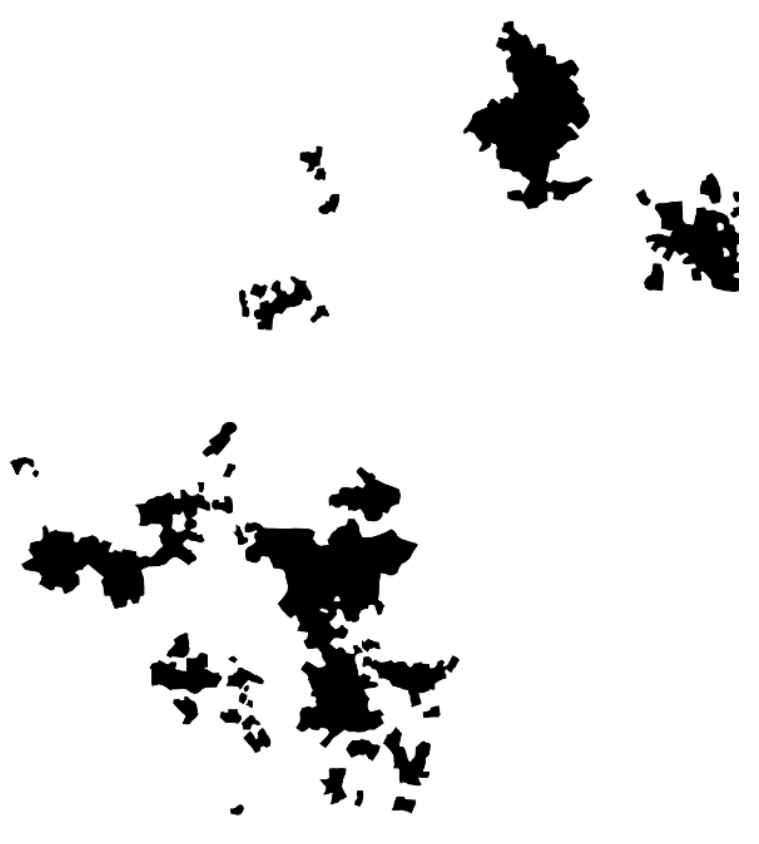


Der westlich der Oder gelegene Teil der preußischen Monarchie (1791)
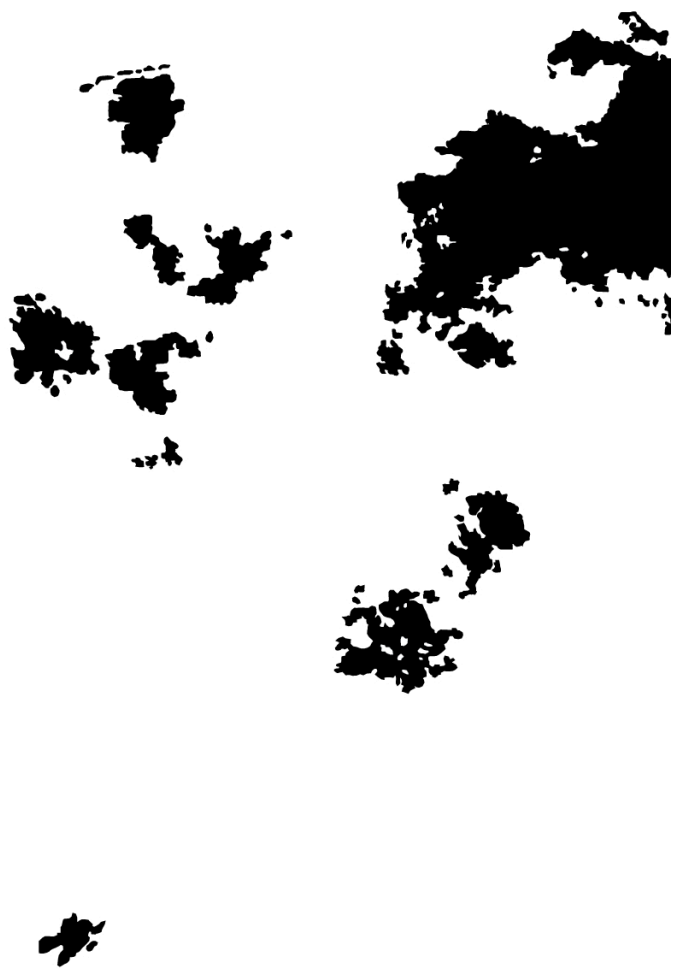

Die Kurpfalz (1789)

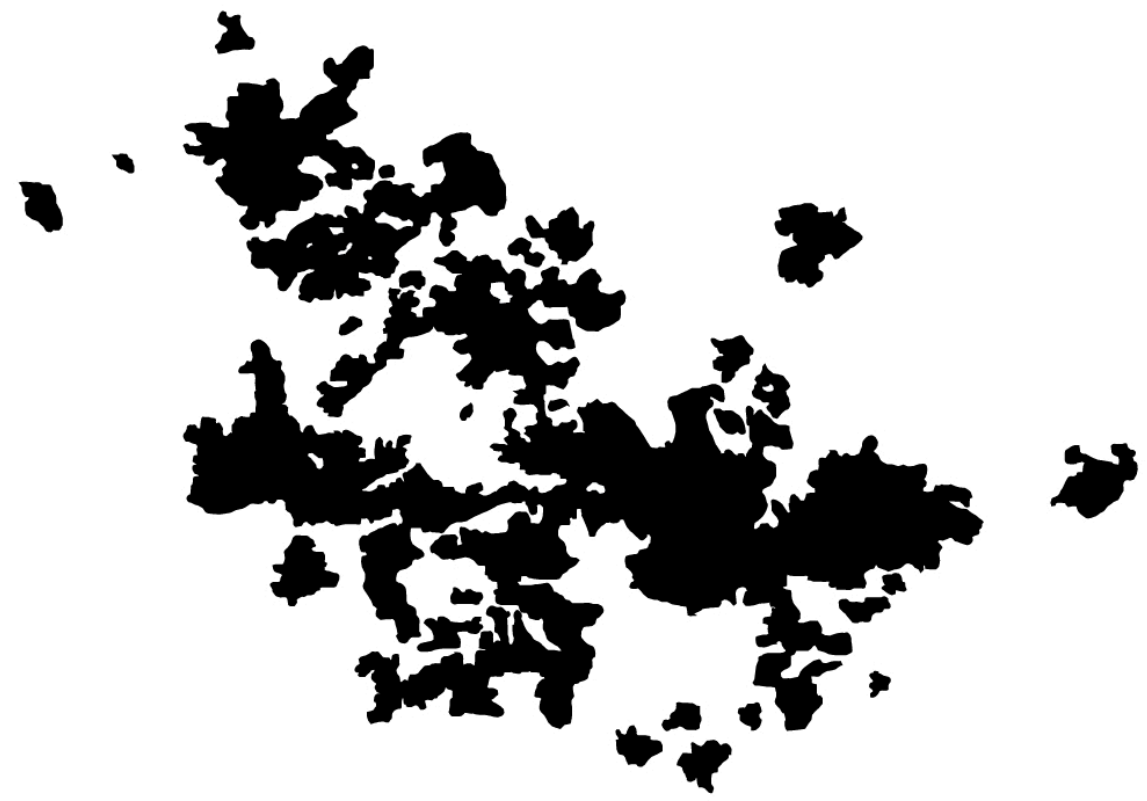

3 In Hinsicht auf das Thema des vorliegenden Bandes - Räume der Macht, Räume der Identifikation - ist diese Allgegenwart der Exklave nicht ohne Bedeutung. Sie macht auf 
eine Struktur des Raum und der politischen Macht aufmerksam, die für das Alte Reich am Ende der Frühen Neuzeit kennzeichnend war. Gleichwohl hat das Phänomen kaum die Aufmerksamkeit der Historiker auf sich gezogen. Zwar fehlt es nicht an gelehrten landeshistorischen Abhandlungen zur Entwicklungsgeschichte und zum juristischen Status dieser oder jener Exklave. Viele Fragen aber bleiben einstweilen weitgehend offen, und auch in diesem Text werden wir uns in der Regel damit begnügen müssen, diese Fragen $\mathrm{zu}$ stellen anstatt sie zu beantworten: Wie wurden administrative Anweisungen oder Anzeigen in eine Exklave überbracht? Was bedeuteten Begriffe wie Zölle und (mehr noch) Territorialgrenzen unter diesen Bedingungen? Fühlten sich die Einwohner einer Exklave einem größeren Ensemble zugehörig, und wenn ja, welchem?

4 Wir werden zunächst sehen, was die geographische Fragmentierung für den Begriff des Territoriums im Alten Reich selbst bedeutete. Danach werden wir uns mit der Wahrnehmung der Exklave durch ihre Einwohner befassen. Schließlich werden wir uns dem negativen Verdikt zuwenden, dem dieser Typ territorialer Komplexität am Ende der hier betrachteten Periode verfiel.

\section{Exklave und Territorium}

5 Die Allgegenwart der Exklave ist zunächst eine Bestätigung dafür, dass der deutsche Territorialstaat der Frühen Neuzeit nicht mit jener »absolutistischen« Elle gemessen werden kann, für die das französische Modell steht (von den Infragestellungen, die der Begriff des »Absolutismus« selbst seit einigen Jahren erfährt, ganz abgesehen). Dass es im Alten Reich eine Vielzahl »kleiner Versailles« gegeben hat und dass einige Fürsten stehende Heere aufbauten, kann nicht über eine auch am Ende des 18. Jahrhunderts noch recht lebendige Wirklichkeit hinwegtäuschen: Der deutsche Territorialstaat hatte auch in jenen Jahren immer noch viel mit einer Ansammlung von Besitztiteln zu tun, er reflektierte also vor allem eine grundherrliche und keine territoriale Logik, und er funktionierte im Rahmen einer ausgedehnten Adelsrepublik, dem Alten Reich.

\section{Teilung, Erbe, Gerichtsbarkeit}

6 Zunächst war der Territorialstaat also eine Ansammlung von Besitztiteln: Zahlreiche Exklaven verdankten ihre Existenz den Modalitäten der Vermögensübertragung in den großen deutschen Adelsfamilien. Dort war über lange Zeit eine Gleichbehandlung aller Erben vorherrschend, was die Notwendigkeit mit sich brachte, die Fürstentümer aufzuteilen. Geachtet wurde dabei auf eine gleichmäßige Aufteilung der Einkommen und ihrer Quellen sowie auf eine Gerichtspraxis, die keinen Inhaber von einzelnen Ansprüchen benachteiligte und teilweise gemeinsam ausgeübt wurde. Auf die räumliche Stetigkeit des Territoriums hingegen wurde bei diesen Teilungen kaum Rücksicht genommen. Das galt nicht nur für die großen Fürstentümer. Auch bei der Aufteilung der winzigen Reichsgrafschaft Ysenburg beispielsweise, die 1684-1687 in vier verschiedene Gebiete zerteilt wurde, entstanden acht Exklaven. ${ }^{6}$ Die untenstehende Karte macht diese räumlichen Konsequenzen der Prinzipien einer Erbfolge deutlich, die keiner territorialen Konzeption folgte: Die Teilung Holsteins im Jahr 1544 brachte es auf die Schaffung von nicht weniger als 17 Exklaven in einem Ensemble, das ziemlich klein und ursprünglich noch dazu relativ homogen gewesen war. 


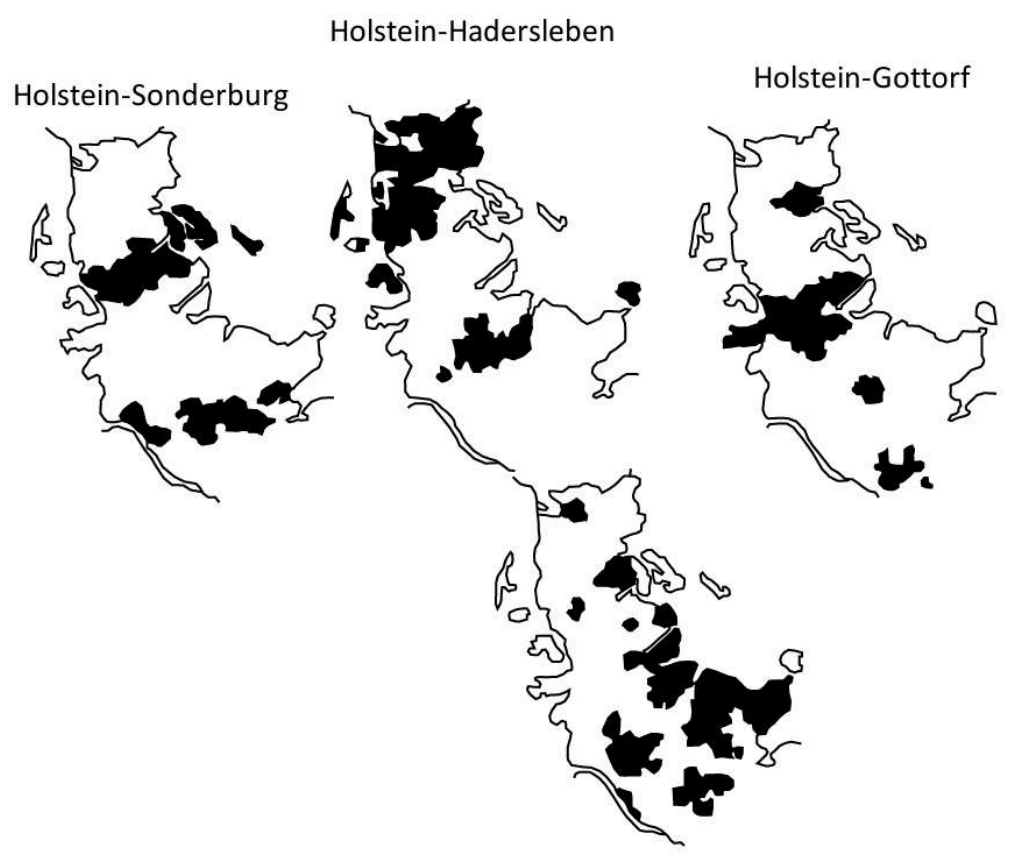

Kondominate

Solche Erbteilungen wurden in Deutschland bis zum Ende des 17.Jahrhunderts vorgenommen. Einige der unübersichtlichsten politischen Landschaften des Reichs wie Thüringen oder das aktuelle Rheinland-Pfalz - sind direkt aus ihnen hervorgegangen, zumal sich zu diesen Teilungen anschließend noch die Erbfolgen zwischen den verschiedenen Linien der jeweiligen Herrscherfamilien gesellten. Auch das Erlöschen einer Dynastie zeigte ähnliche Ergebnisse. Oftmals war sie auf lange Zeit voraussehbar und weckte deshalb unter den anderen fürstlichen Familien Begehrlichkeiten, die in der Regel vom Kaiser nach einem Verteilungsschlüssel geschlichtet wurden, der weit stärker vom Gleichgewicht im Reich und von komplexen politischen Gegenleistungen bestimmt wurde als vom Prinzip räumlicher Kontinuität. Beim Aussterben der Grafen von Henneberg im Jahr 1583 etwa rissen sich mehrere mächtige Nachbarn um die Stücke dieses im Thüringischen gelegenen Territoriums. Dabei entstanden eine Exklave Hessen-Kassels (die Herrschaft Schmalkalden) und eine Exklave Kursachsens (das Suhler Land), die für lange Zeit Bestand hatten. ${ }^{7}$ Auch die sich sehr langsam durchsetzende Primogenitur änderte schließlich nichts Wesentliches an den Grundlagen des Problems, denn sie schrieb die aus vergangenen Perioden überkommene Zersplitterung nur fest. ${ }^{8}$

7 Dieser besitzrechtliche Charakter der deutschen Fürstentümer ging Hand in Hand mit ihrer vorwiegend von der Rechtspflege bestimmten Natur. Zentral war hier weiterhin das komplexe Geflecht von verschiedenen Gerichtszuständigkeiten, denen dieses Dorf oder jene Institution unterworfen waren. Hervorgegangen waren sie aus einer lange Reihe von Feudalabtretungen, Tausch, Erbschaften, Verkäufen und Verpfändungen, und sie befanden sich durchaus nicht immer in einer Hand. Außerdem erwiesen sie sich immer wieder als ein hemmender Faktor, denn in diesem Bereich hatte unbedingten Vorrang, wer den älteren Rechtstitel vorweisen konnte. Grund dafür war das 
Reichsrecht, das die Beziehungen zwischen den als "unmittelbar" bezeichneten Reichsgliedern (den direkt vom Kaiser abhängenden Fürsten und Reichsstädten) regelte und ein pedantischer Bewahrer historisch gewachsener Strukturen war. Der Begriff »Territorialstaat« ging aus dieser Ansammlung von Herrschaftsrechten erst allmählich hervor. Zum wichtigsten, wenn auch noch umstrittenen Kriterium der "Landeshoheit« wurde dabei die Hochgerichtsbarkeit, an deren Seite nach und nach andere Hoheitsrechte traten (etwa das Recht, die Konfession der Untertanen bestimmen zu können, oder das - freilich beschränktere - Recht auf Steuererhebung). Dabei entstand zunehmend eine Hierarchie der Gerichtsbarkeiten, die erst den für die Herausbildung des staatlichen Charakters der reichsunmittelbaren Reichsglieder notwendigen Spielraum schuf. Allerdings: Dieser Prozess vollzog sich ausschließlich im rechtlichen Bereich, (noch) nicht aber im Raum. Gepflogenheiten, die Ausgangsbasis waren für zum Teil kuriose und winzigste Exklaven der Rechtsprechung, überdauerten somit bis zum Verschwinden des Alten Reichs im Jahr 1806: Das Gericht zu Mattsee beispielsweise befand sich zwar auf dem Territorium des Fürsterzbischofs von Salzburg, gehörte rechtlich aber zu Bayern. Wer dort zum Tode verurteilt wurde, musste deshalb auf dem Wasserweg zur Hinrichtung nach Bayern gebracht werden. Der Herzog von Bayern wiederum verfügte in Salzburg und im Marktflecken Straßwalchen über einen »extraterritorialen« Ort, um dort bestimmte ökonomische Rechte und Gerichtszuständigkeiten ausüben zu können. An eben diesen ort, der mitten im Erzbistum Salzburg gelegen war, wurden auch Delinquenten "ausgeliefert«, die den Gerichten des bayerischen Nachbarn unterstanden. ${ }^{9}$

\section{Allgegenwart und Schwäche der Grenze}

Die Vielzahl der Exklaven war also ein Symptom für den besitzrechtlichen und judikativen Charakter, den sich der Territorialstaat des Alten Reichs bewahrt hatte. Gleichzeitig hatte sie Konsequenzen für die Art und Weise, wie sich dieser Staat dem Raum einschrieb. Denn die Schwierigkeiten, die er hatte, um die von ihm erlassenen Vorschriften zu übermitteln und durchzusetzen, wurden durch die Existenz der Exklaven nur noch verstärkt. Besonders hingewiesen werden soll hier deshalb auf eine dieser Konsequenzen: die Allgegenwart von Grenzen.

Was genau das Wesen der Territorialgrenze im Alten Reich ausmachte und welche konkreten Praktiken sich mit ihr verbanden, diese Fragen haben das Interesse der Historiker ebenso wenig auf sich gezogen wie das Phänomen der Exklave. ${ }^{10}$ Dabei gab es nur wenige Orte im Reich, an denen die Menschen weiter als einen Tagesmarsch von einer territorialen Begrenzung entfernt lebten. Die Exklaven vermehrten die Länge der Grenzen um ein Beachtliches und trugen dazu bei, dem Reich den Charakter eines fraktalen Objekts $\mathrm{zu}$ verleihen, das seine Aufteilung in Territorialstaaten gleichermaßen veranschaulichte und relativierte: veranschaulichte, weil die Grenzen Ausdruck waren für die Vielfalt und die Autonomie der Territorialstaaten, und relativierte, weil sie gleichzeitig auf allen Ebenen die Kohärenz und die Möglichkeiten dieser Staaten, sich jeweils individuell zu entfalten, beschnitten.

10 Auf das Adjektiv »fraktal « zurückzugreifen, erscheint legitim, denn die Fragmentierung als Wesenszug des Reichs fand sich auf allen Ebenen wieder. Um sich davon zu überzeugen, reicht es aus, sich anhand der drei folgenden Abbildungen die Silhouetten von Territorialstaaten vor Augen zu führen, die in ihrer Größe deutlich differierten. 
Weiter oben haben wir bereits drei Kurfürstentümer betrachtet. Schauen wir uns deshalb jetzt ein Territorium von geringerer Größe an, das Fürstentum PfalzZweibrücken: Das Bild ist auf genau die gleiche Art und Weise zersplittert. Wir können auch einen noch größeren Maßstab wählen und uns einem der unzähligen geistlichen Mikro-Staaten in Schwaben zuwenden: der reichsunmittelbaren Abtei Weingarten. Auch hier finden wir die gleiche territoriale Zusammenhanglosigkeit. Und wenn wir schließlich die kleine Reichsstadt Nördlingen und ihr Umland betrachten, können wir feststellen: Die territoriale Stetigkeit ist auch hier keinesfalls stärker ausgeprägt.

Pfalz-Zweibrücken (1793)

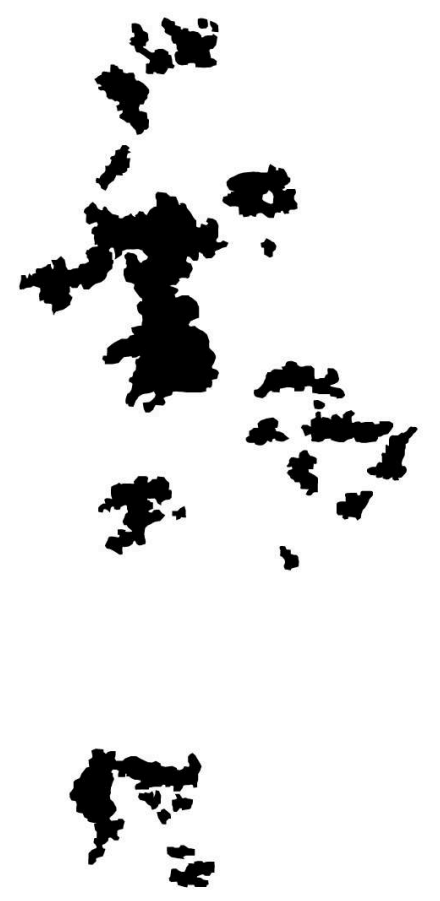


Reichsunmittelbare Abtei Weingarten
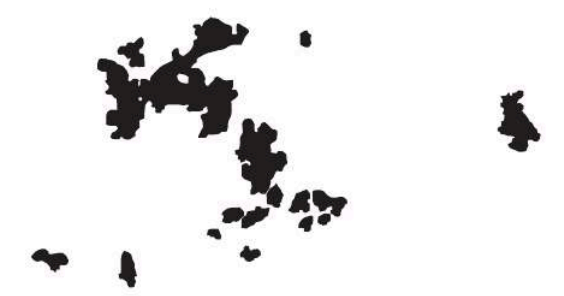

Reichsstadt Nördlingen

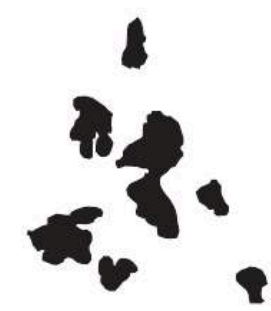

0

$30 \mathrm{~km}$

Warum einer der großen Juristen des ausgehenden 18. Jahrhunderts, Justus Möser, schrieb, die Territorien des Alten Reichs bestünden nur "aus lauter Grenzen «"11, wird nun besser verständlich. Das Wenige, was wir über die Geschichte von Zöllen, 
Grenzüberwachung oder die Einrichtung von Quarantänezonen bei Epidemien wissen, muss durch diese Brille betrachtet werden. Und mehr noch, der Begriff der Territorialgrenze selbst wird durch diese Realität infrage gestellt. Wer glaubte, diese Grenze sei auch nur im Geringsten dicht gewesen, verabschiedete sich von jeder Idee an Bewegung. Und er negierte alle Möglichkeiten, territoriale Gebilde, deren einzelne Bestandteile oft durch eine Unzahl solcher Grenzen voneinander getrennt waren, überhaupt in ihrem Bestand zu erhalten und zu regieren.

11 Aufgrund dieser räumlichen Merkmale kann der deutsche Territorialstaat deshalb letztlich angemessen nur im Zusammenhang mit einer anderen Ebene erörtert werden: dem Raum des Reiches insgesamt.

\section{Territorialer Raum und Einheit des Reichs}

12 Vom Kitt des Reichs zusammengehalten wurde das Mosaik der Territorialstaaten auf zweifache Weise. Auf der einen Seite verliehen der Kaiser und die großen Institutionen des Reichs (der Reichstag und die beiden Reichsgerichte ${ }^{12}$ ) der Fragmentierung der Territorien und mit ihr der hohen Zahl von Exklaven Dauerhaftigkeit. Das trifft selbst auf den weniger zerstückelten und reichsferneren Norden zu. Dort war beispielsweise die Grafschaft Oldenburg zwischen 1525 und 1625 in 80 Prozesse verwickelt, die wegen Grenzstreitigkeiten vor dem Reichskammergericht geführt wurden. So gelang es der Grafschaft am Ende einer sich über mehr als einhundert Jahre (1548-1683) hinziehenden Auseinandersetzung zwar, sich eine auf der östlichen Flanke gelegene Exklave des Hochstifts Münster einzuverleiben; echte Möglichkeiten, ihre Grenzen nach Belieben zu arrondieren und zu glätten, hatte sie aber nicht. ${ }^{13}$ Stärker - und für längere Zeit - noch galt dies für die Fürstentümer im zerstückelten Süden des Reichs. Dass der Kaiser die Territorien gegeneinander ausspielte, versetzte ihn zwar nicht in die Lage, eine monarchische Form seiner Herrschaft durchzusetzen. Es ermöglichte ihm aber, die Macht der Fürsten immer wieder zu beschneiden und größtenteils zu verhindern, dass die bedeutendsten Territorien ihre Exklaven zu einem homogenen Herrschaftsraum zusammenführten, indem sie ihre kleineren Nachbarn einfach annektierten. ${ }^{14}$ Sehr aufschlussreich ist in dieser Hinsicht ein Blick auf die Liste jener Abteien in Schwaben, denen es gelang, ihre Reichsunmittelbarkeit (also ihre Anerkennung als autonomes Fürstentum des Reichs) zu erlangen (Ottobeuren 1624, Kaisheim 1656, Zwiefalten 1751, Neresheim 1764). Den von den benachbarten Dynastien gebildeten territorialen Flickenteppich machte dies nur noch komplizierter. Das Reichsrecht und seine Organe trugen so bis weit ins 18. Jahrhundert hinein eher dazu bei, die territoriale Zersplitterung zu vergrößern als sie zu verringern. Die bloße Lage eines Ortes in einem Territorium galt ihnen jedenfalls keinesfalls als ausreichender Grund, um diesen Ort Teil des Territoriums werden zu lassen. ${ }^{15}$ Und die kaiserliche Gewalt war es auch, die mit Hilfe von Kommissaren die Zulässigkeit und Billigkeit von Erbteilungen überwachte und sanktionierte und so wiederum der territorialen Fragmentierung Vorschub leistete. ${ }^{16}$

13 Auf der anderen Seite machte die Einheit des Reiches den Territorien - trotz ihrer Zersplitterung - eine dauerhafte Existenz dadurch möglich, dass sie den Rahmen für eine Zusammenarbeit und eine ungehinderte Zirkulation von Menschen und Waren bot. So war, wie zwischen allen Territorien des Reichs, auch zwischen territorialen Zentren und ihren Exklaven eine gewisse Handels- und Bewegungsfreiheit gegeben. 
Garantiert wurde diese insbesondere vom Kapitel IX des Westfälischen Friedens. ${ }^{17}$ Die großen Messen, die den Großhandel in seiner Struktur weitgehend - und stärker noch als anderswo in Europa - bestimmten, beruhten so auf kaiserlichen Privilegien, die es den Händlern ermöglichten, sich überwiegend ungestört fortzubewegen. Auch die Straßen, die im 18. Jahrhundert dem französischen Vorbild der Chausseen folgend den Transport und damit die Kommunikation zwischen einer fürstlichen Residenz und ihren Exklaven erleichterten, entwickelten sich zunächst und am stärksten im extrem zerstückelten Süd-Westen des Reichs - und nicht in den großen Territorialstaaten im Osten. ${ }^{18}$ In Auftrag gegeben und ins Werk gesetzt wurden sie von den Reichskreisen, einer Art von regionalen Föderationen, die zu Beginn des 16. Jahrhunderts eingerichtet worden waren und die in einigen Bereichen die Vielzahl von reichsunmittelbaren Herrschaften und ihre Zersplitterung ausgleichen konnten. Keine dieser Herrschaften hätte allein die Mittel aufbringen können, um die Straßen zu bauen, die es brauchte, um über unzählige Grenzen hinweg ihre verschiedenen Teile miteinander zu verbinden; gemeinsam jedoch waren sie in der Lage, ein solches Unternehmen zu realisieren.

14 Ganz besondere Aufmerksamkeit verdient in diesem Zusammenhang ein Beispiel: die Reichspost. Im 16. Jahrhundert gegründet, vermochte es diese Reichsinstitution, nach und nach ein dichtes und leistungsfähiges Netz aufzubauen, das den größten Teil des Reiches abdeckte. Im 18. Jahrhundert war sie dabei so erfolgreich, dass sie die Konkurrenz durch Postunternehmen, die von einzelnen Territorialstaaten eingerichtet worden waren, zurückdrängen konnte. Ebenfalls von ihr eingeführt wurde ein System von Postkutschen, das eine erste Revolution im Bereich des Personentransports darstellte. Anhand des Aufschwungs des Postwesens können wir auch eine Antwort auf eine der Fragen geben, die von der Vielzahl der Exklaven aufgeworfen wird: Wie kommunizierte man zwischen Zentrum und Peripherie? Dieses Problem war durchaus virulent. In Zeiten von kriegerischen Auseinandersetzungen oder Epidemien waren die Verbindungen zwischen den verschiedenen Teilen eines Territoriums oft über Monate hinweg unterbrochen. Und selbst in normalen Zeiten mussten die Verbindungen, mit denen Informationen oder Entscheidungen von einem Ort zum anderen gebracht wurden, durchaus als fragil gelten. In der österreichischen Exklave Triberg im Schwarzwald etwa wurde noch 1791 die gesamte administrative Kommunikation von einem einzigen Träger zu Fuß erledigt, und es kam nicht selten vor, dass auf dem Weg aus seiner zu kleinen Tasche selbst Papiere von höchster Wichtigkeit herausfielen. ${ }^{19}$ Selbstverständlich lief dieser Bote nicht bis nach Österreich, um seine Dokumente abzuholen; er ging bis zur nächsten Station der Reichspost.

Nur die Post war so letztlich in der Lage, die interne Kommunikation in den Territorien zu sichern. Konfessionellen Unterschieden gegenüber war sie neutral, denn als ein der Familie von Thurn und Taxis übertragenes Reichslehen war sie unabhängig von allen Fürstentümern. Der von ihr eingerichtete regelmäßige Linienverkehr war gleichermaßen Antwort auf infra-territoriale Bedürfnisse, die die Kommunikation zwischen den verschiedenen Bestandteilen eines Territoriums betrafen, und auf supraterritoriale Bedürfnisse, die die Ebene des gesamten Reichs berührten. Die folgende Karte versucht deshalb, die Umrisse von Kurmainz und die Routen der Reichspost im Jahr 1764 miteinander zu verbinden. ${ }^{20}$ Sichtbar werden dadurch einige der Etappen, die ein amtliches Schreiben in jenen Jahren hätte nehmen können. Das Ergebnis spricht für sich: Den Zwängen der Territorialgrenzen enthoben, verband die Reichspost ohne Schwierigkeiten die Residenz Mainz über Frankfurt mit zahlreichen Exklaven des 
Kurstaats wie Amöneburg, Fritzlar, das Eichsfeld oder Erfurt. Dabei war die Post nicht ein einziges Mal gezwungen, ihren "reichischen" Korridor zu verlassen und die Territorien benachbarter Fürsten zu berühren.

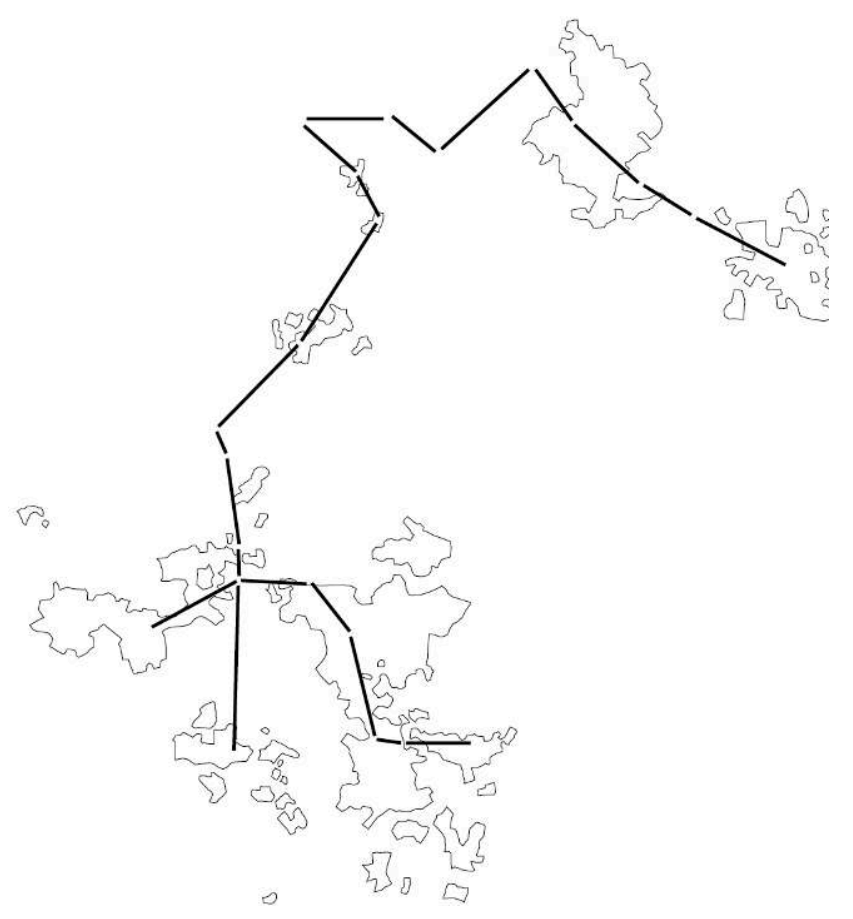

Ausgehend von räumlichen Charakteristika ist die Exklave also (wie die Grenze auch) ein guter Indikator, um die Gestalt des Territorialstaates im Alten Reich zu erfassen. Dieses Staatswesen wurde in Teilen von aristokratischen Besitztiteln geprägt und nicht von einer abstrakten, mit einem Territorium zusammenfallenden Souveränität. Wer sich ihm nähern will, muss seine Beobachtungen auf mehreren Ebenen ansiedeln: von der lokalen Ebene, die vom Wirrwarr der Grenzen bestimmt wurde, bis zur übergreifenden Ebene des Reichsrechts und der Reichsinstitutionen. Am Wesentlichen vorbei geht hingegen seine immer noch anzutreffende Reduzierung auf die Dimension einer speziellen territorialen Herrschaftsform, die letztlich nur als spezifische Variante einer allgemeinen Form verstanden wird, nämlich der des europäischen Staates der Frühen Neuzeit.

Wer die sich im Fraktalen ausdrückende Besonderheit des deutschen Territorialstaats berücksichtigt, kommt im Übrigen auch schnell dazu, sich etwas näher mit den Räumen der Identifikation zu beschäftigen. Bietet uns dieser Bereich die gleiche Komplexität und das gleiche Spiel der Ebenen? Und ist die vom Lokalen bis zum Übergreifenden reichende Skala, die sich als unverzichtbar für das Verständnis politischer Karten erwiesen hat, ebenfalls auf den »Identitätskarten« der sozialen Nutzungen des Raumes vorhanden? 


\section{Exklave und Identität}

18 Die wenigen Arbeiten, die untersucht haben, wie sich die Einwohner des Reiches räumlich und politisch einordneten, scheinen die Vielheit der Referenzebenen $\mathrm{zu}$ bestätigen. Der lokalen Ebene kam dabei zwar eine herausgehobene Rolle zu, die territoriale Ebene aber war bestens bekannt und die regionale Ebene (Franken, Schwaben) durchaus im Blickfeld. Das Auftauchen der Reichsebene hingegen hing von den Umständen ab - der Fall war dies beispielsweise bei Reiseberichten, wie sie Axel Gotthard untersucht hat ${ }^{21}$, oder bei Zeugenbefragungen von Bauern im Verlauf von Prozessen um die Festlegung von Grenzen zwischen mehreren Territorien. Einer dieser Prozesse fand beispielsweise Ende des 16. Jahrhunderts statt und betraf die Dörfer, um die sich die Stadt Nördlingen mit den Grafen von Öttingen stritt - lauter MikroExklaven, deren Silhouette wir bereits gesehen haben. Die betroffenen Bauern wussten vor allem, wer ihnen Geld abverlangte, und auch, wer die Jagdrechte innehatte. Weniger eindeutig waren sie, wenn es darum ging zu sagen, wer ihr "Landesherr« sei. Der Begriff war für sie schon deutlich abstrakter, wobei zu berücksichtigen ist, dass wir uns noch im 16. Jahrhundert und in Schwaben befinden (der am stärksten zerstückelten Region des Reichs). Einer unter ihnen antwortete sogar: »man wisse in Pflaumloch von keinem Landesherr zu sagen«. Und manch anderer zögerte nicht $\mathrm{zu}$ verkünden, Landesherr sei »hre Kaiserliche Majestät« höchstpersönlich. ${ }^{22}$

19 Alles das erlaubt es kaum, mit Bestimmtheit zu sagen, als Einwohner welcher Einheit sich die in einer Exklave lebenden Menschen empfanden. Auf der einen Seite veranschaulicht die Unterschiedlichkeit der Antworten die Exklave als einen Ort, an dem sich das Spiel der den Raum des Reiches charakterisierenden Ebenen besonders deutlich bemerkbar machte. Auf der anderen Seite jedoch machen gerade die Umstände der Befragungen auf die wichtige Rolle aufmerksam, die den lokalen Gemeinschaften bei der Definition von Raum und Macht zuerkannt wurde. Anhand von drei Indikatoren - die Landtage, die Rolle der Kommunen, der konfessionelle Faktor wollen wir diesen Weg weiterverfolgen.

\section{Exklaven und Landtage}

20 Die Landtage - also jene in der Regel vom Adel dominierten Versammlungen, die wichtige Finanzrechte ausübten - wurden vom Reichsrecht geschützt. Nur selten gelang es Fürsten, ihren Einfluss zumindest teilweise abzuschütteln. Der brandenburgische Kurfürst, seit 1702 König in Preußen, gehörte dazu - zumindest, was Brandenburg und Preußen betraf.

21 Als Friedrich II. von Preußen jedoch 1744, bei der Zusammenführung seiner Krone mit einer neuen Exklave (nämlich Friesland), mit den Forderungen des friesischen Landtags konfrontiert wurde, regelte er das Problem mit einer höchst simplen Randnotiz: »vous n'avez qu'à leur accorder tout «. ${ }^{23}$ Dabei folgte er nur dem bereits in früheren Jahren von zwei großen rheinischen Exklaven, der Mark und Kleve, vorgegebenen Beispiel. Hier hatten die Landtage nicht nur eine wichtige Machtposition behalten, der lokale Adel erlangte 1649 auch das Indigenatsrecht, d. h. einen exklusiven Zugang zu einem Großteil der Verwaltungsämter ${ }^{24}$ Die Exklave bekleidete damit einen ähnlichen Status wie ein tatsächlich autonomes und in »Personalunion« mit dem Zentrum befindliches Territorium. Ein solcher Eindruck herrschte -wenn auch mit zunehmenden 
Beschränkungen - in den zahlreichen Exklaven der preußischen Monarchie durchaus vor. ${ }^{25}$ Die Landtage dieser peripheren Regionen blieben zwar von den Entscheidungen in der Regierungszentrale ausgeschlossen. Vor Ort allerdings waren sie eine Gewähr für die Autonomie und Selbstbezogenheit des kleinen Territoriums, wobei es - wie $1736 \mathrm{im}$ Fall von Krefeld - mitunter sogar gelang, die Befreiung vom System der militärischen Rekrutierung nach Kantonen zu erkaufen. ${ }^{26}$

Diese Vitalität der Landtage in den Exklaven scheint recht allgemeiner Natur gewesen zu sein. ${ }^{27}$ Mitunter ging dies soweit, dass die Exklave den Rang eines Zweitterritoriums einnahm (oder behielt), das sich in Personalunion mit dem Stammterritorium befand. Das galt umso mehr, als sie bei passender Gelegenheit als Sekundogenitur für eine jüngere Seitenlinie dienen konnte. Das war beispielsweise der Fall von Mömpelgard (Montbéliard), einem atypischen kaiserlichen Lehnsgut, das regelmäßig als Zuflucht für einen Zweig der Familie der Herzöge von Württemberg fungierte. Diese Entwicklung hatte im Übrigen nicht nur Nachteile für die fürstlichen Dynastien: Württemberg erreichte so auf dem Reichstag von 1559 das Recht, dass seine Abgesandten zweimal abstimmten - einmal für Württemberg und ein zweites Mal für die Grafschaft Mömpelgard. Der Westfälische Frieden von 1648 institutionalisierte dieses Verfahren. Er erlaubte Fürsten, die von den Säkularisierungen der geistlichen Territorien profitiert hatten, auf dem Reichstag die Stimmen dieser Territorien weiterzuführen und somit ihren Einfluss dort zu vergrößern. ${ }^{28}$ Dieser Sieg des Territorialprinzips über das Personenprinzip auf dem Reichstag vollzog sich also nicht zum Nachteil der Autonomie der Exklaven, sondern zu ihrem Vorteil.

Die Untersuchung der Landtage zeigt mithin, dass die Exklaven nicht nur eine Unterbrechung in der räumlichen Kontinuität der Territorien waren. Vielmehr stellten sie auch politische Abspaltungen der Bestandteile dieser Territorien dar, deren sich die Eliten, insbesondere der Adel, durchaus bewusst waren. Deshalb wurden sie immer wieder eingefordert und verteidigt.

\section{Exklaven und kommunale Autonomie}

Allerdings handelte es sich hier um die bedeutendsten Exklaven, die fast eigenständige Fürstentümer waren. Die Silhouetten, die wir gesehen haben, zeigen oft genug aber erheblich kleinere territoriale Staubkörnchen, über die wir ebenso nur fragmentarisch unterrichtet sind. Oder besser: Was wir von Dorfgemeinden in den stark zerstückelten Regionen des Reiches wissen, verknüpft sich nur selten mit ihrem Status als Exklave oder als Grenzdorf. Häufig waren sie jedoch in genau einer solchen Situation: Im Reich des 18. Jahrhunderts fielen die Ränder des Gemeindelandes in einer nicht zu vernachlässigenden Zahl von Fällen mit der Grenze eines Territoriums zusammen. Unter diesen Umständen war der politische Referenzrahmen gleichermaßen lokal, konkret und territorial. Dabei bot die räumliche Nähe einer Fremde, die so wenig fremd war wie das Nachbarterritorium, zahlreiche Möglichkeiten. Man konnte fliehen (wobei der Begriff durchaus übertrieben ist, führte die »Flucht« in der Regel doch nur in die unmittelbare Nachbarschaft) oder die Leistungen des anderen in Anspruch nehmen, wenn die örtliche Obrigkeit zu streng in ihren Anforderungen war bzw. nicht zur Genüge auf die Forderungen der Bevölkerung einging. Gleichzeitig begünstigten die Entfernung vom politischen Zentrum und vor allem die räumliche Isolation eine hohe lokale Autonomie. 
25 Alles das bedeutete jedoch keinesfalls das Vorherrschen einer Art von territorialer Anomie. In der Schwarzwälder Grafschaft Hauenstein, einer Habsburger Exklave, verfügten die Bauern so über einen sehr hohen Grad organisierter Autonomie. Der wesentliche Teil von Verwaltung und Justiz wurde durch Einungsmeister erledigt, die jedes Jahr von der Gesamtheit der verheirateten Männer in den die Grafschaft bildenden Dörfern gewählt wurden. ${ }^{29}$ Bei jedem Versuch des lokalen Herrschaftsinhabers, seinen Durchgriff auf die Bauern zu erhöhen, sandten diese in stark ritualisierten Formen Delegationen an den Kaiser ab, der auch ihr Landesherr war - zwischen 1700 und 1750 passierte dies immerhin zwölf Mal. Ihr Ziel war die Verteidigung der bäuerlichen Freiheiten, aber auch die Umgehung intermediärer Gewalten vor Ort, denn praktisch eingefordert wurde von den Bauern die Reichsunmittelbarkeit. ${ }^{30}$ Das Spiel der Ebenen machte sich also auch in der politischen Kultur der ländlichen Exklaven deutlich bemerkbar. Förderlich war es hier Forderungen nach einer kommunalen Selbstorganisation, deren Gewicht in den am stärksten zerstückelten Regionen des Reiches von zahlreichen Studien nachgewiesen worden ist. ${ }^{31}$ Allerdings muss man auch an dieser Stelle nuancieren. Angemeldet wurde ein Anspruch auf starke Autonomie auch von Städten, die sich in ihren eigenen Exklaven bzw. im Umland durchaus als Landesherren aufspielen konnten. Der bekannteste Fall ist Erfurt, das der Mainzer Kurerzbischof 1664 mit Waffengewalt zum Gehorsam zwingen musste. ${ }^{32}$ Ebenso aussagekräftig ist der Fall von Freiburg im Breisgau, eine vorgeschobene Festung der Habsburger, die sich als die wahre Herrscherin der gesamten Umgebung begriff. In diesen Fällen schränkte der Umstand, dass sie Teil einer Exklave waren, die Autonomie der Landgemeinden also ein. ${ }^{33}$

\section{Das Beispiel der konfessionellen Auseinandersetzung}

26 Der dritte Indikator berührt den Bereich des Konfessionellen. Der Riss zwischen Katholiken und Protestanten wurde vom Westfälischen Frieden unter Zugrundelegung der Situation von 1624 festgeschrieben und vertiefte sich mit der Herausbildung von zwei kulturellen Systemen. Dabei legten sich die Scheidelinien zwischen den beiden Konfessionen auf eine umfassendere Weise und in subtileren Formen über das System der Territorialgrenzen und bildeten ebenfalls zahlreiche Exklaven aus.

Die räumliche Vorstellung, die man sich gewöhnlicher Weise von der konfessionellen Spaltung macht - ein protestantischer Nordosten, ein katholischer Südwesten - kann deshalb nur in ihren großen Linien Gültigkeit beanspruchen. Im Detail erfahrbar wurde der religiöse Unterschied nämlich im sozialen Nahbereich. Denn die konfessionelle Grenze war nicht einfach die räumliche Übertragung eines allgemeinen rechtlichen Rahmens, der seit dem Augsburger Religionsfrieden von 1555 und dem Westfälischen Frieden von 1648 die Koexistenz der Religionen auf Reichsebene und ihre Eigenständigkeit auf der Ebene der Territorien festschrieb. Vielmehr war diese Grenze die Matrix der konfessionellen Identitäten, die sich in der Folgezeit entwickelten. D. h. sie drückte sich in den Zeichen der Abgrenzung und in den Zonen von Gleichgültigkeit, im Spott sowie in den Zugeständnissen und Konflikten aus, die den Takt des Alltags wie der außergewöhnlichen Ereignisse zwischen den Konfessionen bestimmten.

In diesem Bereich spielten die Exklaven wiederum eine besondere Rolle. Sie waren isolierte Bastionen einer jeden Konfession und überhöhten oftmals deren charakteristischen Attribute, wobei sie von den jeweiligen Fürsten in dieser Rolle 
bestärkt wurden. So wurden zahlreiche Wallfahrten bewusst in Fragmenten des Raums abgehalten, die katholisch waren und von protestantischen Territorien umgeben wurden. Die Fürsten von Pfalz-Neuburg beispielsweise übertrugen im 17. Jahrhundert das ehemalige Kloster zu Unterliezheim der reichsunmittelbaren Abtei Sankt Ulrich und Afra in Augsburg. In dieser Exklave, die an die protestantischen Ländereien der Grafen von Öttingen grenzte, rief die Abtei eine Wallfahrt nach Sankt Leonhard ins Leben. ${ }^{34}$ Auch Konflikte, in denen gewisse Aspekte der konfessionellen Identitäten ausgeprägt wurden, waren am häufigsten in den Exklaven anzutreffen. Schließlich trug die Konfession dazu bei, die Zugehörigkeit der Exklave zum territorialen Ganzen zu verstärken. Ein Beispiel dafür ist das Eichsfeld, eine mitten im protestantischen Thüringen gelegene katholische Exklave des kurfürstlichen Erzbistums Mainz. ${ }^{35}$ Mehrere Dörfer organisierten hier im 18. Jahrhundert eine Fußwallfahrt in Prozessionsform nach Walldürn, ein bedeutender Wallfahrtsort, der sich in einem anderen Teil des Kurfürstentums befand und sehr viel näher an der Hauptstadt Mainz gelegen war. In einer Supplik beschrieben Einwohner aus einem dieser Dörfer ihre Reise als die »eine[r] Christliche[n] Armee«, die ihre territoriale und konfessionelle Geschlossenheit durch das Überschreiten der Grenzen erlebte. Als 1680 - und vor allem 1722 - ein »ewiges Gebet « eingerichtet wurde, also eine Anbetung des Heiligen Sakraments, die sich im ganzen Kurfürstentum von Kirchgemeinde zu Kirchgemeinde fortsetzte, schrieben sich die Einwohner des Eichsfelds massenhaft in die Bruderschaften ein, die zu diesem Zweck gegründet worden waren. Eine solche Frömmigkeit, die die Exklave sowohl räumlich als auch zeitlich im Territorium verankerte (im Eichsfeld lief das »ewige Gebet" vom 29. September bis zum 3. Dezember um), hatte auch am Ende des 18. Jahrhunderts nichts von ihrer Popularität eingebüßt. In den zahlreichen Suppliken oder Zeugenaussagen von Bauern, die man in den Archiven des Eichsfeld findet, bezeichnen die Bewohner ihre Region oder sich selbst im Übrigen ziemlich häufig als »maynzisch«.

Gleichzeitig zeichnete sich die Exklave jedoch durch eine ihr eigene Undiszipliniertheit aus. Nach Ansicht der Obrigkeiten kam man hier in etwas zu enge Berührung mit den Protestanten. Sogar einige Gewohnheiten der Gegenseite nahm man an. Eine Untersuchung von 1777 offenbarte so den Mainzer Obrigkeiten, dass nahezu alle Kirchenlieder im Eichsfeld in deutscher Sprache waren - wie bei den protestantischen Nachbarn. Das Eichsfeld verfügte vor Ort mit dem Bischöflichen Kommissariat über eine Verbindungsstation in Kirchenangelegenheiten und nahm so in der Tat auf einigen Gebieten eine eigene Richtung. Vor allem aber ließen die Gemeindemitglieder ihrem Pfarrer bzw. dem Kommissar gegenüber eine lebhafte Selbstständigkeit im Geiste erkennen, die sich insbesondere in einer entschiedenen Ablehnung aller aufklärerischen Maßnahmen im Bereich der Frömmigkeit ausdrückte. Die Untersuchung der Konflikte auf diesem Gebiet macht deutlich, wie stark die Einwohner das Spiel mit den Ebenen beherrschten. So drohten sie etwa, direkt an den Erzbischof zu appellieren, oder behaupteten im Gegenteil, vom Generalvikariat in Mainz erlassene Anordnungen hätten sie niemals erreicht. Den Obrigkeiten, die sich in unterwegs verlorengegangenen Korrespondenzen oder zu späten Antworten verhedderten, bürdete dieses Spiel ein erhebliches Handicap auf. ${ }^{36}$

Die Exklaven waren also mit einem stärker ausgeprägten Arsenal konfessioneller Abgrenzung und Konfrontation ausgestattet und gleichzeitig auf singuläre Weise mit der Notwendigkeit konfrontiert, Grundlagen für ein gegenseitiges Verständnis und eine Neutralität im Umgang mit den umgebenden Nachbarn $\mathrm{zu}$ finden. Auf einer 
allgemeineren Ebene bieten sie deshalb oft die besten Beispiele für jene - im Zeitlichen wie im Räumlichen - diskontinuierliche Disposition zur Aufstachelung und zur Gleichgültigkeit, die die konfessionellen Identitäten in einem pluralen Reich charakterisiert. ${ }^{37}$ Ein Gegengewicht zur konfessionellen Homogenität der Exklaven bildeten schließlich auch die ökonomischen Migrationsbewegungen und die Wanderungen vom Land in die Stadt (beide Phänomene unterstützen im Übrigen auch das Anwachsen der katholischen Minderheiten in den Reichsstädten, die in mehrheitlich katholischen Gegenden die Rolle von protestantischen Inseln hatten ${ }^{38}$ ). Um beim Beispiel des Eichsfeld zu bleiben: Hier erörterten die Obrigkeiten die Frage, ob es angemessen sei, in Duderstadt einen protestantischen Gottesdienst zuzulassen. Dabei war eines der sehr pragmatischen Argumente, die von der weltlichen Regierung der Region 1780 zugunsten dieser Option vorgebracht wurden, dass

»derleÿ nütz[lich]e Leute aus den entfernten Katholischen Länderen, denen die hiesige Provinz vielleicht kaum dem Namen nach bekannt ist, sich nicht leicht erhalten laßen dürften, die in benachbarten protestantischen Landen beÿnahe in übersetzter Anzahl befind[lich]e[n] Fabrikanten und Professionisten aber von der häuslichen Niederlaßung in der Stadt Duderstadt wegen dem Abgang eines öffent[lich]en Gottesdienstes abgehalten werden «. ${ }^{39}$

31 Forderungen nach Autonomie, starkes Lokalbewusstsein, aber auch Wissen um die verschiedenen Referenzebenen (lokal, territorial, auf das Reich bezogen, konfessionell) und gesteigerte Verschränkung mit den »Fremden« in der Nachbarschaft, die einem anderen Territorium und/oder einer anderen Konfession angehörten - das sind somit Elemente einer Antwort auf die Frage, ob die Exklave ein Identifikationsraum war. Über die Fragmentierungen eines jeden Territorialstaates hinaus ist es freilich noch einmal der Raum des Alten Reiches insgesamt, der hier zur Debatte steht. Denn die Exklave war kein Defekt dieses Raumes, sondern eines seiner strukturierenden Elemente. Abgebildet wurde von ihr eine sich zwischen mehreren räumlichen Referenzebenen vollziehende Interaktion, die einen ganz besonderen - wenn auch verwirrenden - Teil der Geschichte des Alten Reichs ausmachte.

\section{Die Abwertung der Exklave}

Wollte man nur einer dieser Ebenen den Vorzug geben, führte dies zu einer reduktionistischen Vorgehensweise. Die Geschichtswissenschaft der letzten Jahre hat dagegen die Herausforderung einer Perspektive angenommen, die für verschiedene Richtungen offen ist. Besondere Aufmerksamkeit hat so erfreulicherweise die Ebene der Gemeinden erfahren. Dabei wurde mitunter übers Ziel hinaus geschossen, kann man doch gelegentlich den Eindruck gewinnen, als seien die Quellen für Konfession und Herrschaft allein nur Verhandlungen im Dorf gewesen. ${ }^{40}$ Dabei wurde die Religion in der überwältigenden Mehrheit der Fälle vom Fürsten festgelegt, und zwischen dem brandenburgischen Kurfürst und dem Abt von Weingarten lagen in dieser Hinsicht Welten. Auch die Reichsebene ist von der Geschichtsschreibung der letzten Jahre dem Vergessen entrissen worden, wobei man erneut bisweilen etwas zu weit gegangen ist. So wurde dem Reich zur allgemeinen Überraschung das Prädikat eines Nationalstaats verliehen ${ }^{41}$ oder es ein bisschen rasch zum harmlosen Vorläufer des Föderalismus oder sogar der Europäischen Union gemacht. In der Perspektive anderer Historiker wiederum hat die Ebene der Territorialstaaten nichts von ihren Rang eingebüßt. Ihnen gilt sie weiterhin als einziges historisches Objekt, das es wert ist, in jene Entwicklung 
eingereiht zu werden, die die Aufmerksamkeit aller teleologischen Theorien bündelt: die Modernisierung. Diese Tradition erklärt letztlich auch das nahezu völlige Fehlen einer Behandlung des Phänomens der Exklave in der historischen Literatur - und sie steht in der Nachfolge einer zunehmenden Abwertung der Exklave, die hier wenigstens noch in groben Zügen analysiert werden soll.

In den Augen der Territorialfürsten und ihrer Verwaltungsapparate boten die Exklaven ganz sicher einige Vorteile. Diese waren zunächst strategischer Natur: Manche Exklaven waren gleichzeitig Zitadellen, die den Weg ins Herz des territorialen Ensembles absicherten - wie zum Beispiel Freiburg im Breisgau für die Habsburger, eine Stadt mit sprunghafter demographischen Entwicklung, die so oft gestürmt wie zurückerobert wurde. ${ }^{42}$ Auf der anderen Seite bedeutete die Eroberung einer Exklave, dass man im Besitz eines Pfandes und eines Tauschobjekts war, das sich bei Verhandlungen einsetzen ließ. Daneben boten die Exklaven politische Vorteile: Bayern und Österreich übten beispielsweise über ihre Exklaven einen konstanten Einfluss im Schwäbischen Reichskreis aus (auch wenn sie dort nicht Mitglied waren), und den Hohenzollern gelang es über die späte Wiedererlangung der Markgrafschaften Bayreuth und Ansbach, in ihrem ursprünglichen Kreis (Franken) wieder Fuß zu fassen. ${ }^{43}$ Im Allgemeinen wies die Exklave schließlich, wie gesehen, einen Autonomiestatus auf, der sie nahezu zu einem "auswärtigen" Bestandteil in räumlichen Ensembles machte, deren gebräuchliche Bezeichnung als »territoriale Fürstentümer" sich als irreführend erweist, suggeriert sie doch eine räumliche und institutionelle Kontinuität, die nur selten verwirklicht werden konnte. Gleichzeitig konnte sie in Einzelfällen aber ganz im Gegenteil ein dem Fürsten äußerst nützliches "Jagdreservat« bilden, das als Reserve an Land und Gerichtsrechten den Nachgeborenen der Dynastie eine Möglichkeit eröffnete, ihren Rang zu bewahren. Und mitunter waren Exklaven auch Machtbastionen für die regierende adlige Oligarchie. Schlesien ist ein gutes Beispiel für die erste dieser Optionen, obwohl es nach seiner faktischen Annektierung 1741 keine Exklave der preußischen Monarchie im eigentlichen Sinne bildete: Friedrich II. machte aus der Provinz eine königliche Staatsdomäne, die von einem ihm direkt unterstellten Minister abhängig war (und nicht vom Generaldirektorium, das der preußischen Verwaltung vorgesetzt war) und deren Einkünfte in seine Privatschatulle flossen. ${ }^{44}$ Auf die zweite Option griffen die Württemberger, die Wittelsbacher und die Wettiner zurück. Die dritte schließlich realisierten beispielsweise die adligen Stiftsherren des Mainzer Domkapitels, die durch ihr Recht auf die Wahl des Kurfürst-Erzbischofs die Rolle von "Ko-Regenten« errungen hatten und das Monopol auf eine ganze Reihe von prestigereichen Funktionen beanspruchten: Dazu gehörten die Ämter der Statthalter an der Spitze der beiden wichtigsten und am entferntesten gelegenen Exklaven des Kurfürstentums (Erfurt und das Eichsfeld), auf die die Stiftsherrn seit 1675 ein Vorgriffsrecht hatten und die ihnen nach 1763 exklusiv übertragen wurden. ${ }^{45}$

In der Hauptsache wurde die Exklave jedoch als ein Nachteil angesehen, vor allem nachdem sich die »territoriale« Konzeption der Reichsstände durchgesetzt hatte. Denn die Disqualifizierung der räumlichen Zersplitterung beruhte in der Tat auf äußerst reellen Hindernissen, die dem Ausbau der landesfürstlichen Macht durch die geographische Fragmentierung entgegensetzt wurden. In den Augen der Kameralisten, die den Fürstendienern die beste Art und Weise lehrten, wie sich die Macht ihres Herrn und die Zahlungsfähigkeit seiner Bevölkerung steigern ließen, war das ideale Territorium deshalb homogen, auf harmonische Weise ausgeglichen und mit einer 
rationalen und kontrollierbaren Grenze umgeben. ${ }^{46}$ Von den Silhouetten, die wir gesehen haben, war das weit entfernt. Zwar waren diese Silhouetten die Wirklichkeit, das Ideal der Kameralisten aber lieferte lange Zeit den Maßstab zur Beurteilung dieser Wirklichkeit (auch wenn manche unter diesen Gelehrten, z. B. Pfeiffer, der u. a. dem Kurfürst-Erzbischof von Mainz diente, angesichts der Schwerfälligkeiten der territorialen Zersplitterung vorschlugen, die Zollpolitik gleich an die Reichsgrenzen und nicht mehr an die Grenzen der Territorialstaaten - zu verlagern ${ }^{47}$ ). Tatsache ist, dass die Zersplitterung der Territorien und die Allgegenwart von Grenzen, die Betrug und Schmuggel erleichterten, vor allem die Wirtschaftspolitik und weniger die Wirtschaft selbst bremsten. Die preußische Monarchie etwa musste darauf verzichten, der Akzise-Steuer in ihren prosperierenden Exklaven im Westen die gleiche fördernde oder hemmende Rolle zuzubilligen, die diese im Osten spielen konnte. ${ }^{48}$

Und überhaupt: Welches Prestige ließ sich aus einem Territorium ziehen, das in Dutzende Teile zerfiel? Die machtentschlossenen unter den Fürsten strebten dementsprechend nach der räumlichen Homogenisierung, der Arrondierung. Dabei griffen sie zum Mittel des Kaufs, der Verpfändung, zu Heiraten oder lehnsrechtlichen Investituren ${ }^{49}$, nur selten jedoch zu Eroberungen, die vom Reichsrecht missbilligt wurden. Die Bilanz aller dieser Anstrengungen war gleichwohl durchwachsen: Die auf den Karten wiedergegebenen Silhouetten zeigen die Situation am Ende des Ancien Régime - d. h., sie zeugen von der enormen Widerstandskraft der Exklaven, die von der Schwäche der Territorien und der Schwerfälligkeit des Reichssystems geschützt wurden. Natürlich ist dabei ein Unterschied zu machen zwischen dem Überleben von Exklaven, die große Territorien durchsiebten (z.B. die Herrschaften der reichsunmittelbaren Ritterschaft, die Württemberg löchrig wie einen Käse machten), und dem Zustand eines Fürstentums, das weitgehend ohne mittelbare Stände war. ${ }^{50}$

Im 18. Jahrhundert schließlich vermehrten sich gütlich erzielte Abkommen zwischen den Territorialstaaten mit dem Ziel, der Verteilung der Gerichtsrechte eine größere Klarheit zu verleihen und die Grenzen linearer werden zu lassen. Abgesehen von den Grenzberichtigungen mit Frankreich (die ausgiebiger untersucht worden sind), schloss beispielsweise die Markgrafschaft Baden-Baden 1707 ein solches Abkommen mit der Kurpfalz und 1775 mit Pfalz-Zweibrücken..$^{51}$ Eine ähnliche Abmachung wurde 1766 zwischen dem Fürstbistum Freising und Tirol geschlossen. ${ }^{52}$ Zwischen Bayern und dem Hochstift Augsburg war die Lage hingegen so verwickelt, dass erste Versuche früh ansetzen mussten und vier Anläufe notwendig waren: Nach Vereinbarungen in den Jahren 1549, 1571 und 1669 erreichte erst der Vertrag von 1785 die Festlegung einer quasi-linearen Grenze im Bereich der Gerichts- und Hoheitsrechte. ${ }^{53}$ Diese auf Vereinfachung ausgerichteten Übereinkommen, die eine exakte Erhebung der Rechtsverhältnisse und die schwierige Festlegung eines Gleichgewichts im Austausch der Ländereien und Vorrechte voraussetzten, stießen sich darüber hinaus häufig genug am Widerstand der Bevölkerungen, die befürchteten, bei diesem Geschäft überkommene Vorteile zu verlieren, die eng mit dem Labyrinth der Gerichtsgrenzen und Zuständigkeitsbereiche verflochten waren. Ein kleines Territorium konnte es sich kaum erlauben, über solche Proteste hinwegzugehen, zumal diese nicht selten von der Drohung mit einer Revisionsklage vor den Reichsgerichten begleitet wurden. Die nach mühsamen Verhandlungen 1721 erreichte Vereinbarung zwischen dem Fürstbischof von Freising und dem Fürstabt von Ettal konnte so erst 1736 in Kraft treten, nachdem die von der Gemeinde Garmisch vorgebrachten Beschwerden berücksichtigt worden waren. ${ }^{54}$ Unter diesen Bedingungen wird verständlich, warum die Grenzberichtigungen 
von begrenztem Ausmaß waren und unvollständig blieben. Der 1777 geschlossene und 1779 vollzogene Vertrag zwischen Tirol und dem Fürstbistum von Trient über einen gegenseitigen Austausch und eine Vereinfachung der Grenze ließ so eine immer noch erkleckliche Anzahl von Exklaven bestehen ${ }^{55}$ Festgestellt werden kann aber dennoch, dass diese Verträge allesamt zu einer Abwertung der Exklave beitrugen. In den Augen der wichtigsten Fürsten des Reichs waren diese zu einem territorialen Kleingeld geworden, mithilfe dessen man hoffte, die zentralen Teile des jeweiligen Territoriums arrondieren zu können. Während des Bayerischen Erbfolgekriegs 1777 nahm Österreich so noch einmal die bayerischen Exklaven in Schwaben zum Unterpfand. In den nachfolgenden Verhandlungen spielte Kaiser Joseph II. hingegen mit der Idee, die Gesamtheit seiner eigenen Besitzungen in Schwaben - also jenes "Vorderösterreich", das lange Zeit als unverzichtbar für den Einfluss der Habsburger im Reich angesehen worden war - einzutauschen. ${ }^{56}$

Dieser beharrliche Wille zur Arrondierung der Territorien hatte letztlich einen nur begrenzten Erfolg - bis zu dem Zeitpunkt, an dem Napoleon kam und das Reich in sich zusammenstürzte. Die wichtigsten Reichsfürsten begnügten sich bei dieser Gelegenheit nicht damit, zu ihren eigenen Gunsten die Zahl der Territorialstaaten drastisch zu reduzieren. Sie "glätteten« auch die Grenzen überall dort, wo es möglich war, und ließen die meisten Fälle geographischer Diskontinuität von den Landkarten verschwinden.

Den Sieg trug also die Ebene der Territorialstaaten davon, in deren Logik die Exklaven vor allem Hindernisse darstellten (für die Reichsebene galt das erheblich weniger). Ebenfalls auf dieser Ebene konstituierte sich auf dem Umweg über Preußen die Einheit später neu. In der Folgezeit haben die Historiker dann ihre Energie darauf verwandt, diesen Sieg in eine historische Notwendigkeit umzudeuten (darin glichen sie ihren französischen Kollegen, die der Ebene von Staat und Nation auf gleiche Weise eine historische Notwendigkeit zusprachen). Damit setzte sich die idealistische Perspektive der territorialen Verwaltungsspitzen auf die Exklaven durch. Sie galten nun gleichermaßen als Relikte der Vergangenheit, als räumliche Anomalien und als hemmende Faktoren der Macht. Sie existierten im Übrigen nicht einmal mehr: In den großen Geschichtsatlanten ist (zugegebenermaßen auch aus technischen Gründen) alles, was zu klein oder zu kompliziert erscheint, in ein unschuldiges Weiß getaucht. Mit anderen Worten: Die Untersuchung der Exklaven fand sich von nun an abgeschoben in den lauschigen Dämmerschlaf der Lokalgeschichtsschreibung.

\section{Schlussfolgerungen}

Unsere Ausführungen zu den Exklaven bewegen sich also auf dem schmalen Grat zwischen zwei Felsklippen. Auf der einen Seite steht das Desinteresse für einen Gegenstand, der nachgerade als widerwärtig erschien, aufgrund seiner winzigen Größe bestenfalls als Tummelplatz einer Minderheit galt und insgesamt als ohne Relevanz angesehen wurde. Auf der anderen Seite hingegen steht das Gefühl, die Exklaven und das Reich, in dessen Schoß sie gediehen, im Namen irgendeines Lokalpatriotismus mit reaktionären Zügen »rehabilitieren« zu müssen. Verurteilung und Emphase gehören jedoch beide gleichermaßen abgelöst durch eine analytische Sicht auf die Exklaven, die sie auf der Ebene jener Interaktionen und Antagonismen verankert, die den komplexen Schichtungen des Raums im Alten Reich Leben einhauchten. Denn letztlich ist die 
Exklave ein Symptom neben anderen für die charakteristischen Merkmale des Raums des frühmodernen Reiches: nicht eine überkommene »räumliche Schwerfälligkeit«, die in der Folgezeit wie ein autonomer Faktor agierte, sondern eine in den institutionellen und politischen Strukturen verankerte Besonderheit, die sich in bestimmte soziale Nutzungen des Raumes übertrug. Dass sich diese Nutzungen in einem Wechselspiel von Wiederholungen und Modifikationen zum Teil bis heute erhalten haben und in einem Land fortdauern, in dem die Menschen in Fritzlar oder dem Eichsfeld (beides ehemalige Kurmainzer Exklaven) deutlich häufiger CDU wählen als in den umliegenden Gegenden, das könnten dann die Kenner der Zeitgeschichte berichten.

\section{BIBLIOGRAPHIE}

Ackermann, J. (2002): Verschuldung, Reichsdebitverwaltung, Mediatisierung. Eine Studie zu den Finanzproblemen der mindermächtigen Stände im Alten Reich: Das Beispiel der Grafschaft YsenburgBüdingen, 1687-1806, Marburg: Hessisches Landesamt für Geschichtliche Landeskunde, S. 12-21.

Baumgart, P. (1984): „Die Annexion und Eingliederung Schlesiens in den friderizianischen Staat«, in: Baumgart, P. (Hg.): Expansion und Integration. Zur Eingliederung neugewonnener Gebiete in den preußischen Staat, Köln / Wien: Böhlau, S. 81-118.

Behringer, W. (2003): Im Zeichen des Merkur. Reichspost und Kommunikationsrevolution in der Frühen Neuzeit, Göttingen: Vandenhoeck \& Ruprecht.

Buschmann, A. (1994) (Hg.): Kaiser und Reich. Verfassungsgeschichte des Heiligen Römischen Reiches Deutscher Nation vom Beginn des 12. Jahrhunderts bis zum Jahre 1806 in Dokumenten, 2. Aufl., BadenBaden: Nomos.

Carl, H. (1999): »)Ein rechtes anomalum८ - die umstrittene reichsrechtliche Stellung Mömpelgards«, in: Lorenz, S. / Rückert, P. (Hg.): Württemberg und Mömpelgard. 600 Jahre Begegnung / Montbéliard - Wurtemberg. 600 ans de relation, Leinfelden-Echterdingen: DRW-Verlag, S. 347-363.

Christ, G. (1989): „Selbstverständnis und Rolle der Domkapitel in den geistlichen Territorien des alten deutschen Reiches in der Frühneuzeit«, Zeitschrift für historische Forschung, 16, S. 257-328.

Dörrer, F. (1984): „Die >limitierte Landeshoheit` der Bischöfe von Trient und Brixen in Beziehung zur gefürsteten Grafschaft Tirol«, in: Riedenauer, E. (Hg.): Landeshoheit. Beiträge zur Entstehung, Ausformung und Typologie eines Verfassungselements des römisch-deutschen Reiches, München: Kommission für Bayerische Landesgeschichte, S. 135-144.

Dotzauer, W. (1998): Die deutschen Reichskreise (1383-1806). Geschichte und Aktenedition, Stuttgart: Steiner.

Duhamelle, C. (2002): „De la confession imposée à l'identité confessionnelle. Le cas de l'Eichsfeld, XVIe-XVIIIe siècles«, Études Germaniques, 57, S. 513-527.

Duhamelle, C. (2003): »Les Jésuites de Heiligenstadt et le pélerinage du Hülfensberg à l'époque moderne«, Revue Mabillon, n.s. 14, Bd. 75, S. 203-224. 
Duhamelle, C. (2004): »Frontière, territoire, confession: l'exemple de l'Eichsfeld «, in: Lebeau, C. (Hg.): L'espace du Saint-Empire du Moyen Âge à l'époque moderne, Straßburg: Presses universitaires de Strasbourg, S. 175-192.

Duhamelle, C. (2005): »)Die Kuh` und die srote Mütze«: Gemeinde, Pfarrer und Obrigkeit im Eichsfeld in der Zeit der Aufklärung«, in: Hartmann, P. C. / Pelizaeus, L. (Hg.): Forschungen zu Kurmainz und dem Reichserzkanzler, Frankfurt/M.: Peter Lang, S. 7-27.

Eckhardt, A. (1984): »Hoheits- und Grenzauseinandersetzungen in Reichskammergerichtsprozessen im Zeitalter der Konsolidierung des Territorialstaats im 16. und frühen 17. Jahrhundert anhand nordwestdeutscher Beispiele«, in: Diestelkamp, B. (Hg.): Forschungen aus Akten des Reichskammergerichts, Wien: Böhlau, S. 75-97.

Eimers, E. (1983): »Das Ständewesen in Ostfriesland «, in: Baumgart, P. (Hg.): Ständetum und Staatsbildung in Brandenburg-Preußen, Berlin: De Gruyter, S. 409-423.

Engeleit, H.-G. / Rothe, J. M. (1989): »Das Indigenatsrecht in Lippe. Eine Untersuchung zum Verhältnis von Adel und Verwaltung im 17. und 18. Jahrhundert«, Lippische Mitteilungen, 58, S. 95126.

François, É. (1989): „Dans un Empire pluraliste: les dynamiques contraires de l'exclusion et de la cohabitation«, in: Media in Francia. Recueil de mélanges offert à Karl Ferdinand Werner, Maulévrier: Hérault éditions, S. 187-198.

François, É. (1991): Die unsichtbare Grenze: Protestanten und Katholiken in Augsburg 1648-1806, Sigmaringen: Thorbecke.

Fried, P. (1984): „Die Landeshoheits- und Grenzverhältnisse zwischen dem alten Bayern und den schwäbischen Territorien: Landeshoheitsrechte in Gemengelage«, in: Riedenauer, E. (Hg.): Landeshoheit. Beiträge zur Entstehung, Ausformung und Typologie eines Verfassungselements des römischdeutschen Reiches, München: Kommission für Bayerische Landesgeschichte, S. 61-68.

Gabel, H. (1995): Widerstand und Kooperation. Studien zur politischen Kultur rheinischer und maasländischer Kleinterritorien (1648-1794), Tübingen: bibliotheca academica.

Garner, G. (2004): »La question douanière dans le discours économique en Allemagne (seconde moitié du XVIIIe siècle)«, in: Lebeau, C. (Hg.): L'espace du Saint-Empire du Moyen Âge à l'époque moderne, Straßburg: Presses universitaires de Strasbourg, S. 39-53.

Garner, G. (2005): État, économie, territoire en Allemagne. L'espace dans le caméralisme et l'économie politique 1740-1820, Paris: Éditions de l'EHESS.

Gotthard, A. (1999): Säulen des Reiches: Die Kurfürsten im frühneuzeitlichen Reichsverband, Husum: Matthiesen.

Gotthard, A. (2003): „Vormoderne Lebensräume. Annäherungsversuch an die Heimaten des frühmodernen Mitteleuropäers«, Historische Zeitschrift, 276, S. 37-73.

Grube, W. (1975): Vogteien, Ämter, Landkreise in Baden-Württemberg, Bd. 1: Geschichtliche Grundlagen, Stuttgart: Kohlhammer.

Heinritz, G. / Heller, H. / Wirth, E. (1968): »Wirtschafts- und sozialgeographische Auswirkungen reichsritterschaftlicher Peuplierungspolitik in Franken«, Berichte zur deutschen Landeskunde, 41, S. 45-72.

Heller, H. (1971): Die Peuplierungspolitik der Reichsritterschaft als sozialgeographischer Faktor im Steigerwald, Erlangen: Palm \& Enke. 
Herz, H. (1992): »Zu einigen Problemen der Landesteilungen in Thüringen vom 16. bis zum Beginn des 19. Jahrhunderts«, Zeitschrift des Vereins für Thüringische Geschichte, 46, S. 147-159.

Hohkamp, M. (1998): Herrschaft in der Herrschaft. Die vorderösterreichische Obervogtei Triberg von 1737 bis 1780, Göttingen: Vandenhoeck \& Ruprecht.

Jany, C. (1981): „Die Kantonverfassung des altpreußischen Heeres«, in: Büsch, O. / Neugebauer, W. (Hg.): Moderne preußische Geschichte 1648-1947: Eine Anthologie, Berlin: De Gruyter, S. 767-809.

Klein, T. (1982): »Verpasste Staatsbildung? Die wettinischen Landesteilungen in Spätmittelalter und früher Neuzeit«, in: Kunisch, J. / Neuhaus, H. (Hg.): Der dynastische Fürstenstaat. Zur Bedeutung von Sukzessionsordnungen für die Entstehung des frühmodernen Staates, Berlin: Duncker \& Humblot, S. 89-114.

Kullen, S. (1984): »Reichsritterschaft und Siedlungsbild«, in: Quarthal, F. (Hg.): Zwischen Schwarzwald und Schwäbischer Alb: Das Land am oberen Neckar, Sigmaringen: Thorbecke, S. 221-270.

Lausser, H. (1977): »Die Wallfahrten des Landkreises Dillingen. Der Versuch einer Wallfahrtstypologie unter dem Gesichtspunkt ihrer Verwendung als Mittel zum Ausbau oder zur Festigung von Herrschaft durch ideologische Einflussnahme auf die Untertanen «, Zeitschrift für Bayerische Landesgeschichte, 40, S. 75-119.

Luebke, D. (1997): „Naïve monarchism and Marian veneration in Early Modern Germany«, Past and Present, 154, S. 71-106.

Motsch, C. (2001): Grenzgesellschaft und frühmoderner Staat. Die Starostei Draheim zwischen Hinterpommern, der Neumark und Großpolen (1575-1805), Göttingen: Vandenhoeck \& Ruprecht.

Müller-Uelthöffer, B. (2003): Der 500jährige Rechtsstreit des Klosters Neresheim um die Erlangung der Reichsunmittelbarkeit. Zugleich ein Beitrag zum Rechtsgang vor den höchsten Reichsgerichten in der Mitte des 18. Jahrhunderts, Frankfurt/M.: Peter Lang.

Noël, J.-F. (1968): »Zur Geschichte der Reichsbelehnungen im 18. Jahrhundert«, Mitteilungen des Österreichischen Staatsarchivs, 21, S. 106-122.

Noël, J.-F. (1997): »La conscience d'Empire en milieu populaire dans l'Allemagne du XVIIIe siècle«, in: Babel, R. / Moeglin, J.-M. (Hg.): Identité régionale et conscience nationale en France et en Allemagne du Moyen Âge à l'époque moderne, Sigmaringen: Thorbecke, S. 119-131. [Dieser Artikel wurde im Rahmen dieses Themenhefts ins Deutsche übersetzt, A.d.R.]

Opgenoorth, E. (1983): „Stände im Spannungsfeld zwischen Brandenburg-Preußen, PfalzNeuburg und den niederländischen Generalstaaten: Cleve-Marck und Jülich-Berg im Vergleich«, in: Baumgart, P. (Hg.): Ständetum und Staatsbildung in Brandenburg-Preußen, Berlin: De Gruyter, S. 243-262.

Opgenoorth, E. (1984): »Die rheinischen Gebiete Brandenburg-Preußens im 17. und 18. Jahrhundert«, in: Baumgart, P. (Hg.): Expansion und Integration. Zur Eingliederung neugewonnener Gebiete in den preußischen Staat, Köln / Wien: Böhlau, S. 33-44.

Press, V. (1975): »Herrschaft, Landschaft und `Gemeiner Mann〈 in Oberdeutschland vom 15. bis zum frühen 19. Jahrhundert«, Zeitschrift für die Geschichte des Oberrheins, 123 (NF 84), S. 169-214.

Press, V. (1982): „Schwaben zwischen Bayern, Österreich und dem Reich 1486-1805«, in: Fried, P. (Hg.): Probleme der Integration Ostschwabens in den bayerischen Staat. Bayern und Wittelsbach in Ostschwaben, Sigmaringen: Thorbecke, S. 17-78.

Press, V. (1994): »Die badischen Markgrafen im Reich der frühen Neuzeit«, Zeitschrift für die Geschichte des Oberrheins, 142 (NF 103), S. 19-57. 
Press, V. (1997): »Absolutismus, Regionalismus und Ständetum im Heiligen Römischen Reich«, in: Babel, R. / Moeglin; J.-M. (Hg.): Identité régionale et conscience nationale en France et en Allemagne du Moyen Âge à l'époque moderne, Sigmaringen: Thorbecke, S. 89-99.

Rath, J. (2003): » Fürstliche Autorität und städtische Autonomie nach 1648. Das Fürstbistum Münster, die Stadt Münster und die Hansestädte«, in: Asch, R. G. / Arndt, J. / Schnettger, M. (Hg.): Die frühneuzeitliche Monarchie und ihr Erbe. Festschrift für Heinz Duchhardt zum 60. Geburtstag, Münster: Waxmann, S. 37-57.

Sahlins, P. (1996 [1989]): Frontières et identités nationales. La France et l'Espagne dans les Pyrénées depuis le XVIIe siècle, Paris: Belin.

Schadek, H. (1994): ")Der Statt Freyburg zugehörige Fleckhen und Dörffer«. Das Territorium der Stadt bis zur Auflösung 1807«, in: Haumann, H. / Schadek, H. (Hg.): Geschichte der Stadt Freiburg im Breisgau, Bd. 2: Vom Bauernkrieg bis zum Ende der habsburgischen Herrschaft, Stuttgart: Theiss, S. 237-251.

Scheffknecht, W. (2002): „Grenzlage, Identitätsbildung und Schmuggel in Spätmittelalter und früher Neuzeit: Der Reichshof Lustenau als Beispiel«, Schriften des Vereins für Geschichte des Bodensees und seiner Umgebung, 120, S. 161-202.

Schindling, A. / Ziegler, W. (Hg.) (1989-1997): Die Territorien des Reichs im Zeitalter der Reformation und Konfessionalisierung. Land und Konfession 1500-1650, 7 Bde., Münster: Aschendorff.

Schmidt, G. (1999): Geschichte des Alten Reiches. Staat und Nation in der Frühen Neuzeit 1495-1806, München: Beck.

Schmidt, H. R. (1997): „Sozialdisziplinierung? Ein Plädoyer für das Ende des Etatismus in der Konfessionalisierungsforschung«, Historische Zeitschrift, 265, S. 639-682.

Schmölz-Häberlein, M. (2003): »Konfessionelle Konflikte in der Markgrafschaft Hochberg in der frühen Neuzeit. Konfliktregulierung und Kommunikation in einem südwestdeutschen Kleinterritorium«, in: Eriksson, M. / Krug-Richter, B. (Hg.): Streitkulturen. Gewalt, Konflikt und Kommunikation in der ländlichen Gesellschaft (16.-19. Jahrhundert), Köln / Weimar / Wien: Böhlau, S. 309-334.

Schnettger, M. (2004): „Le Saint-Empire et ses périphériques: l'exemple de l'Italie«, in: Duhamelle, C. (Hg.): Les espaces du Saint-Empire à l'époque moderne = Histoire, Économie et Société, 1, S. 7-23.

Schwarzmaier, H. (1990): ")Von der fürsten tailungı. Die Entstehung der Unteilbarkeit fürstlicher Territorien und die badischen Teilungen des 15. und 16. Jahrhunderts«, Blätter für deutsche Landesgeschichte,126, S. 161-183.

Schyle, H. (1993): Freiburg i. Br. und seine Einwohner im 17. Jahrhundert, Freiburg: Ploetz.

Stauber, R. (1984): Grenzen und Landeshoheit der Grafschaft Werdenfels in der frühen Neuzeit, in: Riedenauer, E. (Hg.): Landeshoheit. Beiträge zur Entstehung, Ausformung und Typologie eines Verfassungselements des römisch-deutschen Reiches, München: Kommission für Bayerische Landesgeschichte, S. 176-192.

Stollberg-Rilinger, B. (2009): »Le rituel d'investiture dans le Saint-Empire de l'époque moderne: histoire institutionnelle et pratiques symboliques «, Revue d'Histoire Moderne \& Contemporaine, 56 (2), S. 7-29.

Störmer, W. (1972): »Territoriale Landesherrschaft und absolutistisches Staatsprogramm. Zur Mikrostruktur des Alten Reichs im 18. Jahrhundert«, Blätter für deutsche Landesgeschichte, 108, S. $90-104$. 
Ulbrich, C. (1993): „Grenze als Chance? Bemerkungen zur Bedeutung der Reichsgrenze im SaarLor-Lux-Raum am Vorabend der Französischen Revolution«, in: Pilgram, A. (Hg.): Grenzöffnung, Migration, Kriminalität, Baden-Baden: Nomos, S. 139-146.

Ullmann, S. (2002): »Landesherr und Kaiser im Spiegel eines Zeugenverhörs des Reichshofrats aus den Jahren 1575-1579«, in: Fuchs, R.-P. / Schulze, W. (Hg.): Wahrheit, Wissen, Erinnerung.

Zeugenverhörprotokolle als Quellen für soziale Wissensbestände in der Frühen Neuzeit, Münster: Lit Verlag, S. 257-290.

Wunder, B. (1996): „Der Kaiser, die Reichskreise und der Chausseebau im 18. Jahrhundert«, Zeitschrift für Neuere Rechtsgeschichte, 18, S. 1-22.

Zaisberger, F. (1994): »'Das Land und Erzstift Salzburg〈. Ein Beitrag zur Entstehung des Landes und seiner Grenzen«, in: Riedenauer, E. (Hg.): Landeshoheit. Beiträge zur Entstehung, Ausformung und Typologie eines Verfassungselements des römisch-deutschen Reiches, München: Kommission für Bayerische Landesgeschichte, S. 213-235.

\section{NOTES}

1. Schnettger (2004).

2. Genaugenommen ist die Unterscheidung zwischen verschiedenen Typen von Grenzen schwierig. Das Verhalten der Einwohner von Exklaven ist an den Reichsgrenzen besser untersucht, es gibt jedoch auch einige Hinweise auf ihre Vorgehensweisen an den Grenzen zwischen einzelnen Territorien, die von der Forschung bislang stärker im Dunklen gelassen wurden. Vgl. beispielsweise Ulbrich (1993); Motsch (2001); Scheffknecht (2002).

3. Die spanische Exklave Llívia in Frankreich, Campione d'Italia zwischen Italien und der Schweiz, Büsingen zwischen Deutschland und der Schweiz sowie Baarle zwischen Belgien und Holland (Sahlins [1996], S. 320, Anm. 38).

4. Nur die Kondominate, also von mehreren Territorien gemeinsam verwaltete Regionen, sind nicht als solche dargestellt worden. Die Atlanten und Bücher, die für diese Karten benutzt wurden, sind der "Geschichtliche Atlas der Rheinlande« (veröffentlicht von der Gesellschaft für Rheinische Geschichtskunde), der in Lieferungen seit 1982 erscheint und aktuell mehr als 80 Karten und etwa 50 erläuternde Broschüren zählt, der von der Pfälzischen Gesellschaft zur Förderung der Wissenschaft zwischen 1963 und 1994 veröffentlichte »Pfalz-Atlas«, der "Historische Atlas von Baden-Württemberg", der seit 1972 in Lieferungen von der Kommission für Geschichtliche Landeskunde in Baden-Württemberg und dem Landesvermessungsamt BadenWürttemberg veröffentlich wird, der "Große Historische Weltatlas« des Bayerischen Schulbuchverlags in seiner 4. Auflage von 1981 und schließlich Schindling / Ziegler (1989-1997), eine Publikation, die eine Vielzahl leider mitunter vereinfachter oder unvollständiger Karten liefert.

5. Die Kurfürsten, deren Zahl sich im 16. Jahrhundert auf sieben belief, später (mit der Hinzufügung Bayerns zu Beginn des Dreißigjährigen Krieges und Hannovers am Ende des 17. Jahrhunderts) auf acht bzw. neun, hatten u. a. die Funktion, den Kaiser zu wählen. Gotthard (1999).

6. Ackermann (2002), S. 12-21 und beigefügte Karte.

7. Herz (1992), S. $149 \mathrm{f}$.

8. Schwarzmaier (1990); Klein (1982).

9. Zaisberger (1994), S. 231. 
10. So letztens die Feststellung von Gotthard (2003), S. 44: "Zu den Reichsterritorien liegt meines Wissens keine Untersuchung vor, doch weiß jeder Archivbenutzer, wie ausufernd die frühneuzeitlichen Bestände über `Grenzstreitigkeiten` sind.«

11. Störmer (1972), S. 91.

12. Reichshofrat und Reichskammergericht.

13. Eckhardt (1984).

14. Der Kampf gegen die Mediatisierungen (d. h. die Unterwerfung eines Territoriums durch ein anderes) blieb bis zum Ende des Alten Reichs eines der Hauptelemente des Reichsrechts und seiner Anwendung.

15. Müller-Uelthöffer (2003), bes. S. 152 und 204.

16. Herz (1992), S. 154.

17. Buschmann (1994), hier Bd. 2, S. 67 f. Artikel XVII, Abs. 9 regelt seinerseits den Fall eines Durchmarschs von Truppen eines Fürsten durch das Territorium eines anderen (ebd., S. 104).

18. Wunder (1996); Behringer (2003).

19. Hohkamp (1998), S. $70 \mathrm{f}$.

20. Diese Karte ist als Faksimile wiedergegeben in Behringer (2003), S. 768-819.

21. Gotthard (2003).

22. Ullmann (2002); Eckhardt (1984) weist S. 82 auf die interessante Rolle dieser Verhörprotokolle in Grenzauseinandersetzungen hin, wertet sie aber nicht aus. Zur Verbindung zwischen territorialer Zersplitterung und dauerhaftem Zugehörigkeitsgefühl zur Reichsebene vgl. auch Noël (1997) [übersetzt in dieser Ausgabe von Trivium - A.d.Ü.].

23. Eimers (1983), S. 414.

24. Das Indigenatsrecht in Kleve und der Mark war sogar besonders strikt, denn es schloss jeden Ausländer aus, während es sich in anderen Territorien wie Lippe darauf beschränkte, bei zwei gleichwertigen Bewerbern dem lokalen Kandidaten einen Vorzug einzuräumen. Vgl. Engeleit / Rothe (1989), bes. S. 110 f.

25. Auch wenn die Freiheiten (im alten Sinn) dieser Exklaven nach und nach zurückgingen, um den neuen Anforderungen des preußischen Staates Platz zu machen, bestanden sie doch weitgehend bis zum Ende des Ancien Régime fort: Opgenoorth $(1983 ; 1984)$.

26. Jany (1981), S. 787.

27. Press (1997), bes. S. 93-95.

28. Carl (1999), S. $357 \mathrm{f}$.

29. Grube (1975). Die Grafschaft Hauenstein gehört allerdings zu den wenigen österreichischen Exklaven, in denen diese kommunale Autonomie in der zweiten Hälfte des 18. Jahrhunderts erheblich reduziert wurde.

30. Luebke (1997).

31. Vgl. u. a. Press (1975); Gabel (1995); Motsch (2001).

32. Dieser Vorgang schrieb sich in einen allgemeinen Kontext ein, der plausibel dargestellt wird von Rath (2003).

33. Schadek (1994).

34. Lausser (1977), S. 94 f; für ein anderes Beispiel einer Grenzwallfahrt, die in eine katholische Exklave gelegt wurde, vgl. Duhamelle (2003).

35. Duhamelle (2002; 2004).

36. Duhamelle (2005).

37. In der Markgrafschaft Hochberg beispielsweise verschoben die protestantischen Exklaven einige Festtage, um ihren Kalender dem der Katholiken anzugleichen - was jedoch keinesfalls eine Akkumulation von Konflikten in anderen Bereichen verhinderte: Schmölz-Häberlein (2003), S. 314; allgemeiner: François (1989).

38. François (1991).

39. Kommissariatsarchiv Heiligenstadt, Fach 271-2-II, 25. 
40. Vgl. beispielsweise Schmidt (1997).

41. Schmidt (1999).

42. Schyle (1993).

43. Dotzauer (1998), S. 81-179.

44. Baumgart (1984).

45. Christ (1989), S. 293.

46. Garner (2005), bes. S. 166-173.

47. Garner (2004), S. 50-52.

48. Opgenoorth (1984), S. 40.

49. Trotz eines sich nach 1740 zunehmend artikulierenden Widerwillens der größten Staaten des Reichs spielte die Investitur durch den Kaiser weiterhin eine wichtige Rolle im Reich: Noël (1968); Stollberg-Rilinger (2009).

50. Die Eigenarten der politischen, wirtschaftlichen und sozialen Nutzungen des Raumes, die im Fall der Exklaven bislang kaum untersucht worden sind, sind für den Bereich der ritterschaftlichen Exklaven von einigen schon älteren, aber durchaus anregenden Arbeiten in den Blick genommen worden: Heinritz / Heller /Wirth (1968); Heller (1971); Kullen (1984).

51. Press (1994), S. 45.

52. Stauber (1984), S. 186.

53. Fried (1984), S. 64 f.

54. Stauber (1984), S. $182 \mathrm{f}$.

55. Dörrer (1984), S. 141.

56. Press (1982), S. 69. Friedrich II. von Preußen bemühte sich ebenfalls, im Westen gelegene Exklaven gegen Ländereien einzutauschen, die den zentralen Teil seiner Monarchie vergrößert hätten: Opgenoorth (1984), S. 35.

INDEX

Schlüsselwörter : Altes Reich, Exklave

Mots-clés : Saint-Empire, exclave

\section{AUTEURS}

\section{CHRISTOPHE DUHAMELLE}

Christophe Duhamelle ist Directeur d'études an der Ecole des hautes études en sciences sociales (EHESS) Paris. Nähere Informationen finden Sie hier. 